\title{
Olhares sobre a paisagem - a utilização de imagens de satélite e fotografias aéreas no ensino de Geografia
}

RESUMO: A análise de imagens de satélites e fotografias aéreas de diferentes anos auxilia na compreensão da evolução da paisagem e no planejamento do uso e ocupação do espaço. Este trabalho compreende uma discussão da aplicação de uma atividade de ensino com o uso de geotecnologias no ensino fundamental. A prática-pedagógica objetivou o estudo das transformações da paisagem urbana do município de São Leopoldo através da análise e interpretação de fotografias aéreas e imagens de satélites e a elaboração de mapas temáticos digitais. Verificou-se que o uso paralelo destes produtos representa uma ferramenta essencial para realizar análises espaciais da paisagem em transformação e construir noções cartográficas com os alunos.

\section{Perspectives on the landscape - the use of satellite images and aerial photographs in teaching Geography}

ABSTRACT: The analysis of satellite images and aerial photographs from different years can assist in understanding the dynamics of the evolution of landscape and planning the use and occupation of space. This work includes a discussion of the application of a learning activity. This practice-teaching aims the study of the transformations of the urban landscape of city São Leopoldo through analysis and interpretation of aerial photographs and satellite imagery available and the development of digital thematic maps. Was verified that the parallel use of these products and its representation is an essential tool for teaching and make spatial analysis of landscape change, and to build cartographic notion.
Flávio Lopes Holgado* Kátia Kellem da Rosa**

*Mestrando no Programa de PósGraduação em Geografia da UFRGS e professor da rede municipal de ensino de São Leopoldo.

** Doutoranda no Programa de PósGraduação em Geociências na UFRGS e professora substituta no Departamento de Geodésia da UFRGS, ministrando disciplinas de Sensoriamento Remoto.

Palavras-chave: Ensino; Paisagem; Sensoriamento Remoto; Cartografia temática.

Key-words: Education; Landscape. Remote Sensing; Thematic mapping. 


\section{Primeiros olhares...}

Fotografias aéreas e imagens de satélites representam um recurso didático importante para o ensino e pesquisa em Geografia, pois possibilitam uma maior interação do aluno, instigando-os à manipulação e análise de informações. Além disso, possibilitam interpretações das relações dinâmicas no espaço e a sua representação em mapas temáticos.

O uso de geotecnologias em sala de aula para análise da paisagem e suas transformações possibilita a inserção de novos recursos como apoio pedagógico no ensino de Geografia. Sobre isso, Cavalcante e Biesek (2009) salientam a importância do uso destas tecnologias no ensino de Geografia e a necessidade do professor estar atento as novas possibilidades geradas. Observa-se que quanto aos produtos do Sensoriamento Remoto, o professor de Geografia ainda não se aproximou como devia desse recurso. Portanto, é necessário maior envolvimento dos professores, dos diferentes níveis de ensino, para pensar o uso de geotecnologias em sala de aula.

A metodologia utilizada no ensino de Geografia constitui um dos principais motivos das dificuldades de aprendizagem dos alunos, pois de acordo com Francischett (2002) as atividades desenvolvidas em sala de aula, na maioria das vezes, estão desvinculadas da realidade vivenciada pelos alunos. Também contribui para isso a não utilização de outros recursos na prática cotidiana de sala de aula. Assim é necessário que ocorra a

incorporação de outras formas de linguagem (ou outras formas de leitura da realidade), como o cinema, a música, a literatura, as charges, a internet. É verdade que a sociedade mudou e avançou em muitos aspectos, e que a escola e o ensino de geografia não têm acompanhado satisfatoriamente essa mudança. Por isso mesmo, a escola e o ensino de geografia precisam, de fato mudar, precisam estar mais ligados à vida social atual (CAVALCANTI, 2008, p.33).

Torna-se importante a utilização de outros recursos para que ocorram aprendizagens significativas por parte dos alunos, ou seja, a utilização de diferentes formas de trabalho, de outras linguagens. Um dos fatos que contribuem para a deficiência do uso das geotecnologias na escola é a falta de habilitação dos professores para trabalhar com estas possibilidades. Nesta perspectiva, as universidades devem habilitar o professor para trabalhar com as geotecnologias como recurso didático. De acordo com as Diretrizes Curriculares para o curso de Geografia, dentre as competências que o professor de Geografia deve possuir é ler, analisar e interpretar produtos de Sensoriamento Remoto e SIG, e adequar ao processo de ensino-aprendizagem através do desenvolvimento de materiais didáticos.

Desta forma, considera-se importante instigar a inserção de geotecnologias como apoio didático-pedagógico pelos professores de Geografia. 0 professor, assim, passa a ser não apenas um mero observador do desenvolvimento do processo tecnológico no ensino, mas participante utilizando estes meios. De acordo com os Parâmetros Curriculares Nacionais do ensino fundamental, um dos objetivos pretendidos ao ensino de Geografia é habilitar os alunos a

Geografia Ensino \& Pesquisa, v. 15, n.3, p. 129138, set./dez. 2011

Olhares sobre a paisagem - a utilização de imagens de satélite e fotografias aéreas no ensino de Geografia esta inserção, desenvolvendo habilidades de utilização das diferentes fontes de informações e recursos tecnológicos, assim, segundo as orientações sobre o ensino da disciplina, verifica-se a necessidade de inserir esses recursos nas atividades desenvolvidas no cotidiano escolar. $E$ como recurso pedagógico, as fotografias aéreas e imagens de satélite são recursos que contribuem para o aprofundamento do conhecimento geográfico em sala de aula (PONTUSCHKA et al, 2009). 
Importante se faz instigar a utilização de novos recursos didáticos para a renovação das práticas pedagógicas em Geografia, através de uso de computadores, programas de edição de imagem, fotografias aéreas e imagens de satélites. De acordo com Pontuschka et al, (2009), os recursos didáticos quando utilizados de forma adequada possibilitam um melhor desenvolvimento das atividades, melhorando o aproveitamento no processo de ensino e aprendizagem. E esse é o principal objetivo de toda proposta para o ensino, melhorar os resultados em sala de aula. Isto só tem sentido quando se considera que é necessária uma melhora na qualidade do ensino proporcionado aos alunos.

Este artigo desenvolve uma proposta de atividade de ensino sobre a análise das transformações da paisagem urbana com a utilização de fotografias aéreas e imagens de satélites de diferentes anos nas aulas de Geografia. Apresenta uma discussão sobre o uso de geotecnologias em sala de aula para a análise da paisagem em uma turma de sexta série. Durante a prática-pedagógica realizou-se o estudo das transformações da paisagem no centro de São Leopoldo, município onde moram os alunos, através da análise e interpretação de fotografias aéreas e imagens de satélites disponíveis e a elaboração de mapas temáticos. A construção de produtos cartográficos pelos alunos propicia o entendimento do sistema de signos (VYGOSTSKY apud FRANCISCHETT, 2002), condições importantes para o desenvolvimento das aulas de Geografia. Além disso, a elaboração de simbologias apropriadas aos mapas temáticos representando o espaço vivido possibilita ao aluno situar-se no espaço geográfico.

A área analisada sofreu uma intensa modificação ao longo dos anos, demonstrando a ocorrência de um processo de urbanização. Através da utilização das imagens busca-se realizar uma análise da paisagem urbana e desenvolver noções cartográficas. Relacionado ao tema é importante destacar que

A observação da paisagem urbana permite perceber a espacialização das diferentes classes sociais; áreas deterioradas, áreas segregadas, áreas nobres, áreas em processo de valorização são facilmente reconhecidas na paisagem. É também possivel perceber a historicidade da sociedade materializada na paisagem, por meio de formas antigas que permanecem para além das funções que as criam (CAVALCANTI, 2008, p.66).

Assim os alunos podem, com a utilização deste recurso, analisar e refletir sobre paisagens que fazem parte do seu cotidiano. Além de perceber a dinâmica que envolve a criação e modificação do espaço urbano.

\section{Como observar? Como analisar?}

A prática pedagógica apresentada neste texto teve como objetivo desenvolver a análise das transformações da paisagem no centro do município de São Leopoldo através da interpretação de fotografias aéreas e imagens de satélite do Google Earth de anos distintos da área de estudo com uma turma de sexta-série de uma escola pública municipal do mesmo município (Figura 1).

Antes de ser realizada a interpretação das imagens foi trabalhado com os alunos 0 processo de urbanização, analisando-se temas relacionados a este processo ocorrido no Brasil, assim como características e problemas do espaço urbano. Isso possibilitou o embasamento teórico para o desenvolvimento das atividades com os alunos.

Geografia Ensino \& Pesquisa, v. 15, n.3, p. 129138, set./dez. 2011

Holgado, F. L.; Rosa, K. K 


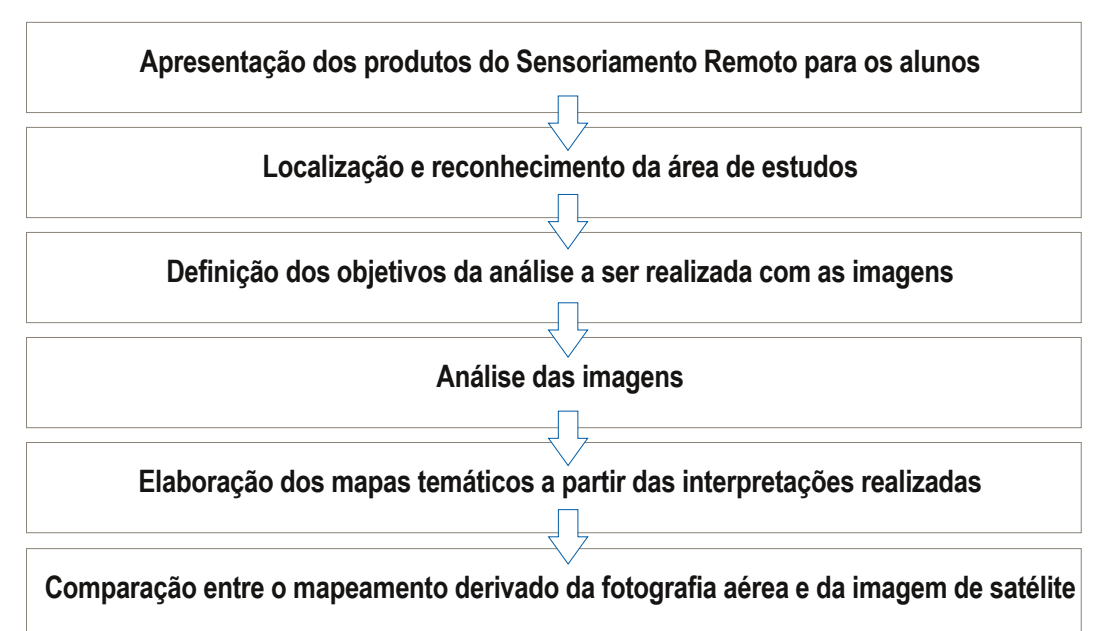

Figura 1 - Fluxograma apresentando a sequência das atividades realizadas.

A seguir, apresenta-se de forma mais detalhada cada uma das etapas desenvolvidas nas atividades didáticas realizadas:

a) Apresentação dos produtos de Sensoriamento Remoto.

Para a realização desta atividade foi apresentado aos alunos o conceito de sensoriamento remoto, e explicitado como os produtos são gerados, como são adquiridos e como podem ser utilizados para os mais variados fins.

b) Apresentação da área de estudo

Através da observação de uma imagem do Google Earth os alunos tomaram conhecimento da área que seria analisada por eles. A imagem foi apresentada utilizando um projetor, propiciando a discussão e percepção das características área de estudo pelos alunos.

c) Definição dos elementos a serem percebidos

Com os alunos foram definidos os objetivos da análise a ser realizada com as imagens. Destacando-se: a análise dos elementos da paisagem e suas transformações; direção da expansão da mancha urbana; uso do solo; áreas de risco; áreas com problema de infra-estrutura urbana; focos de poluição e desmatamento.

d) Atividades com as fotografias aéreas e imagens de satélites

Apresentou-se uma fotografia aérea do centro do município de São Leopoldo, do ano de 1947, contrastando com a imagem do Google Earth atual (2010) da mesma área. Neste momento os alunos, em grupos, interpretaram as imagens. Durante a atividade, discutiu-se com os alunos sobre os diversos elementos que fazem parte das paisagens analisadas e as transformações que podem ser percebidas.

e) Elaboração de mapas temáticos

Utilizando um programa de edição de imagens (GIMP - GNU Image Manipulation Program) os alunos elaboraram a delimitação das áreas presentes nas imagens de diferentes anos (Figura 2 e 3).

Geografia Ensino \& Pesquisa, v. 15, n.3, p. 129138, set./dez. 2011

Olhares sobre a paisagem - a utilização de imagens de satélite e fotografias aéreas no ensino de Geografia 


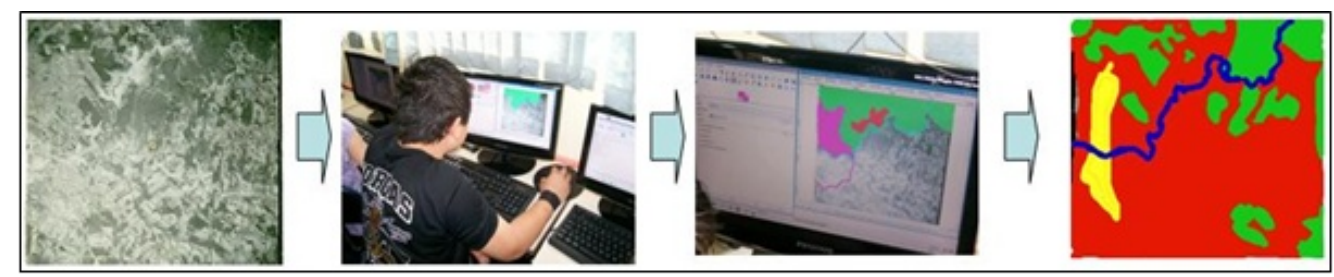

Figura 2 - Fluxograma representando o processo de criação dos mapas temáticos.

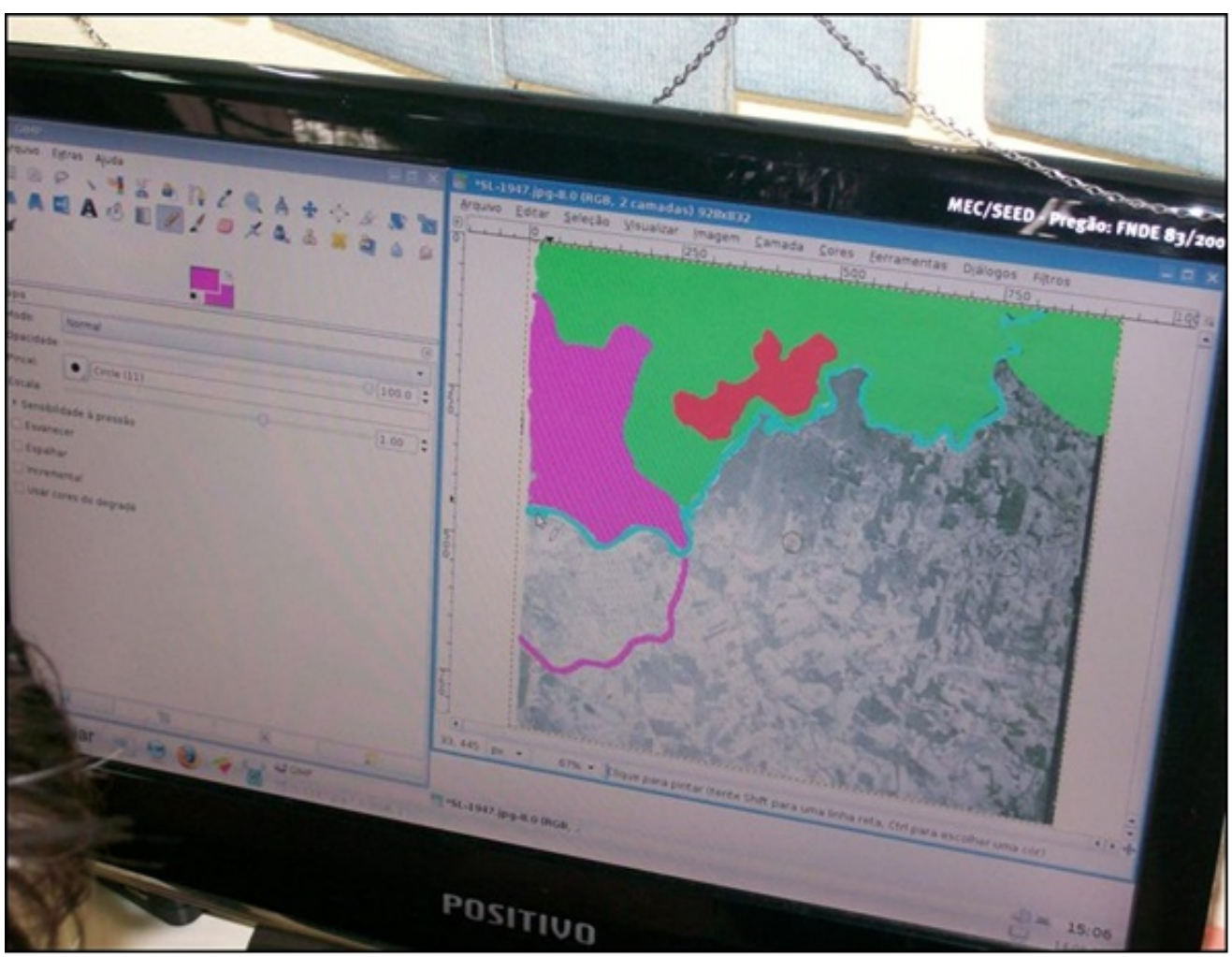

Figura 3 - Mapa temático em fase de construção.

Durante a realização da atividade os alunos demonstraram bastante interesse sobre a proposta. Quando foi realizada a apresentação dos produtos de Sensoriamento Remoto em uma apresentação de slides, os alunos tiveram curiosidade em saber mais sobre como se obtinha esses produtos. Neste momento iniciou-se a análise de algumas imagens para que fossem identificados alguns elementos na paisagem. Isso foi importante para que os alunos conseguissem desenvolver a atividade com a fotografia aérea e com a imagem do Google Earth.

No laboratório de informática da escola os alunos tiveram o primeiro contato com as imagens que seriam utilizadas, foi possível realizar uma primeira análise sobre as imagens. Neste momento os alunos demonstraram muito interesse em relação a sua cidade e as transformações que foi sofrendo ao longo do tempo.

O passo seguinte foi o início da elaboração dos mapas temáticos. Primeiramente, os alunos foram apresentados ao programa de edição de imagens que seria utilizado, o programa GIMP. Surgiram algumas dificuldades na utilização do programa, pois os alunos nunca haviam trabalhando com um programa de edição de imagens, então foi necessário uma atenção maior para explicar a sua utilização. Com a realização da atividade essas dificuldades foram sendo superadas. Cabe destacar que os alunos têm acesso ao laboratório de informática, uma vez por semana, durante o período normal de aula. Isso foi fundamental para o desenvolvimento do

Geografia Ensino \& Pesquisa, v. 15, n.3, p. 129138, set./dez. 2011

Holgado, F. L.; Rosa, K. K 
trabalho, pois não foi necessário ensinar as noções básicas sobre a utilização do equipamento, em especial no uso do teclado e do mouse.

$\mathrm{Na}$ elaboração dos mapas temáticos os alunos conseguiram identificar a maioria dos elementos presentes nas imagens, assim conseguiram delimitar a área urbana, a área rural, a área de vegetação e identificar o curso do rio dos Sinos. Durante a atividade a turma foi orientada pelo professor para a interpretação e identificação dos elementos nas imagens. Podese perceber que as primeiras observações de fotografias aéreas e imagens de satélite feitas na apresentação dos produtos de Sensoriamento Remoto foram importantes para que conseguissem identificar os elementos nas imagens. Após a elaboração dos mapas temáticos os alunos fizeram análises sobre as transformações na paisagem ao longo do tempo.

\section{Analisando a paisagem e indo além do que se vê...}

Com tais atividades, percebeu-se que análises de imagens possibilitam aos alunos realizarem discussões sobre as transformações na paisagem na área de estudo compreendendo o seu município, como foi o caso do centro de São Leopoldo. A seguir, apresentam-se os mapas temáticos elaborados durante a atividade desenvolvida (Figuras 4 e 5).

De acordo com Francischett (2002), o ensino de geografia deve possibilitar a formação de cidadãos preparados para entender e planejar o espaço em que vivem. Assim, a criação de mapas temáticos pelos alunos, a partir de imagens de satélite e fotografias aéreas, promove 0 desenvolvimento de conceitos cartográficos como as categorias de representação (simbologias e localizações), conceitos importantes para o entendimento do espaço. Esta atividade proporciona, desta forma, que os alunos desenvolvam uma análise sobre os espaços que ocupam.

Geografia Ensino \& Pesquisa, v. 15, n.3, p. 129138, set./dez. 2011

Olhares sobre a paisagem - a utilização de imagens de satélite e fotografias aéreas no ensino de Geografia

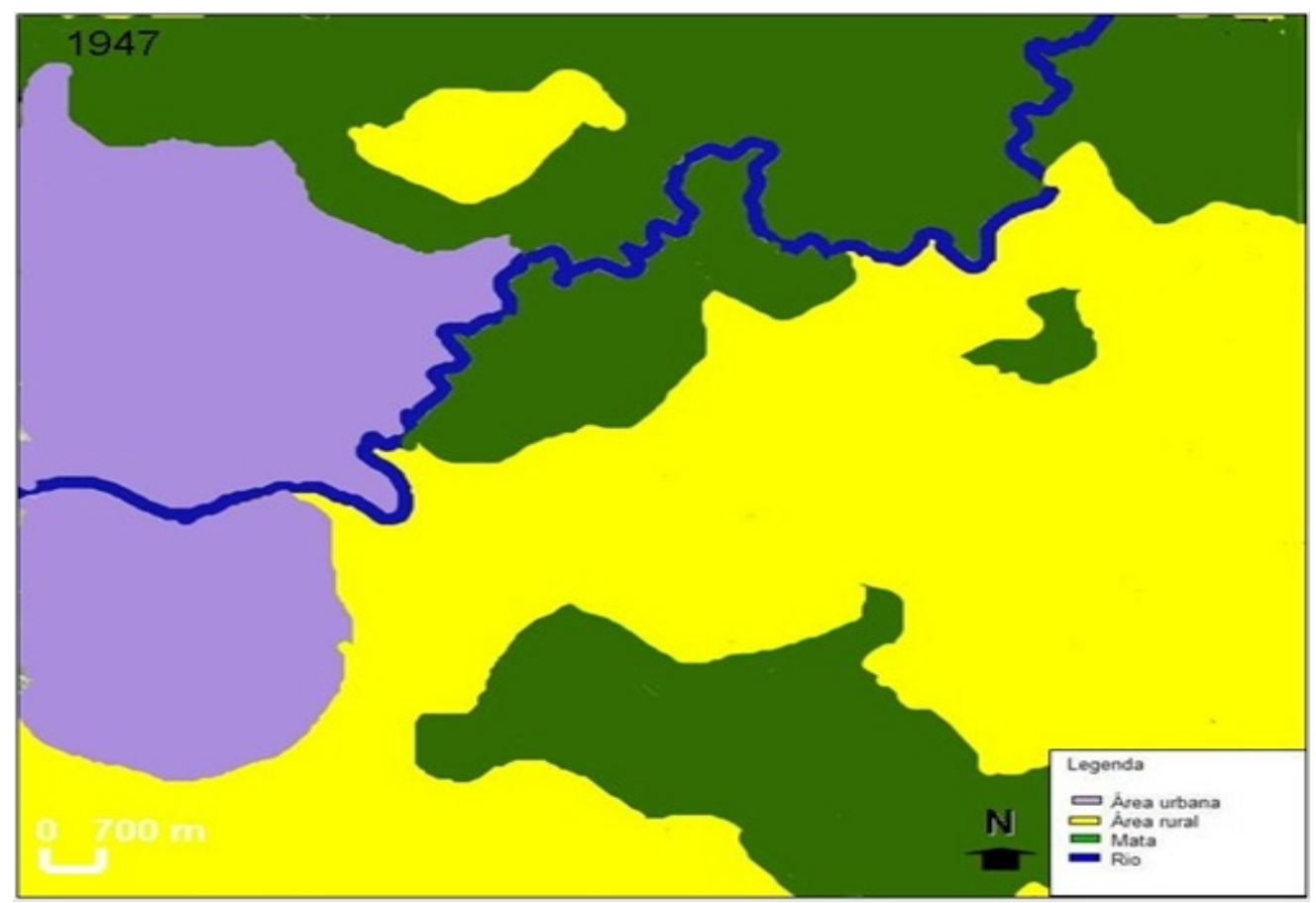

Figura 4 - Mapa temático elaborado por um aluno a partir da fotografia aérea de São Leopoldo - 1947 


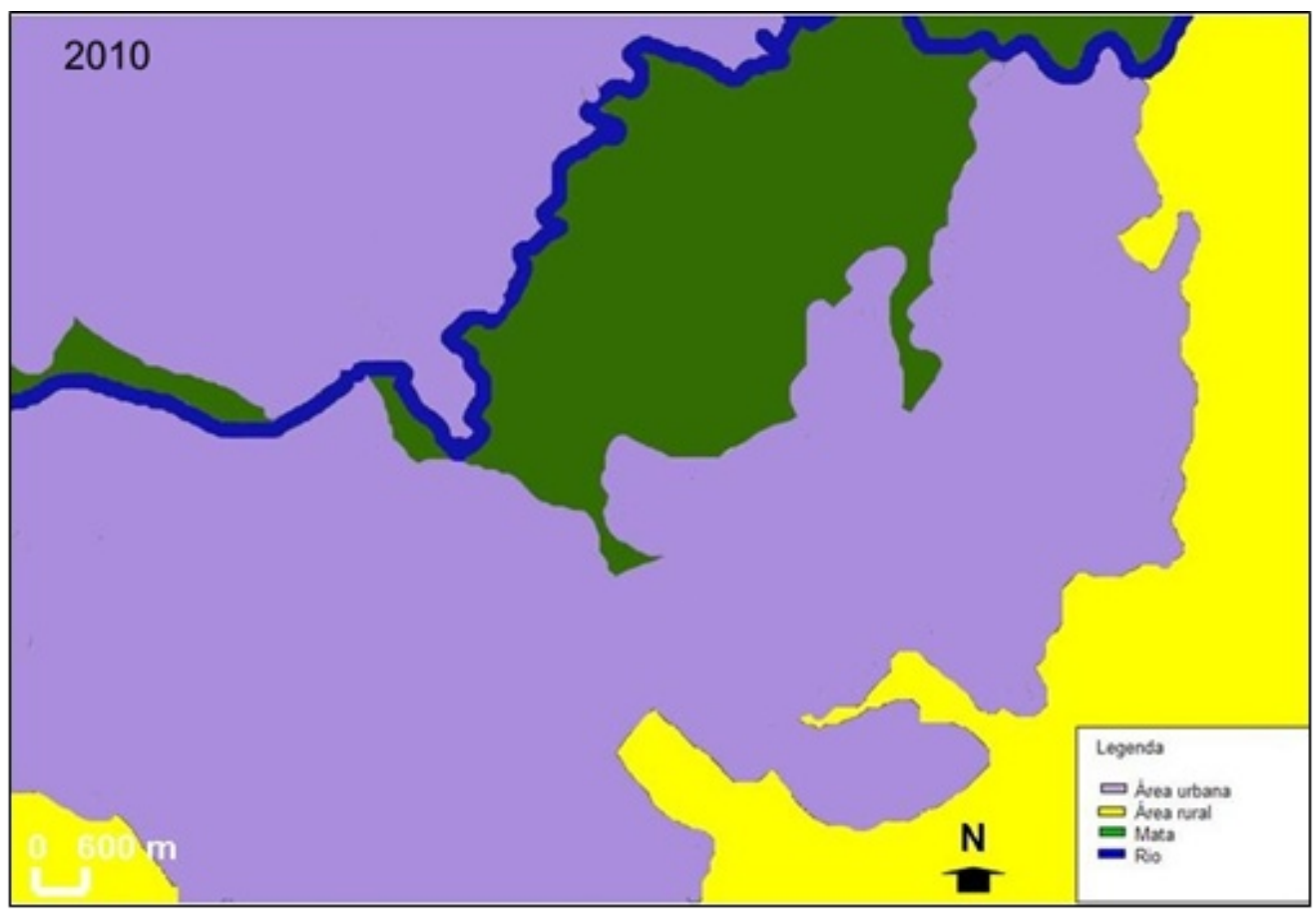

Figura 5 - Mapa temático elaborado por um aluno a partir imagem do Google Earth de São Leopoldo - 2010.

A atividade desenvolvida possibilitou aos alunos conhecer o significado dos símbolos, pois representaram um local que conhecem, o qual faz parte do seu cotidiano. Com a criação do mapa temático, os alunos puderam perceber a generalização dos elementos do espaço e compreender as formas de ocupação deste.

Ao fazerem as análises, os estudantes mencionam as modificações na paisagem ao longo do período, destacaram a diminuição da área rural e a expansão da área urbana, com a consequente diminuição da cobertura de vegetação no local. Além disto, perceberam situações como aumento da poluição, a qual pode estar relacionado ao crescimento da urbanização. Isto foi verificado pelos alunos com a comparação entre produtos de Sensoriamento Remoto de distintos anos. Então com a observação mais atenta das imagens e dos mapas temáticos possibilitou que desenvolvessem uma relação entre diferentes processos que podem gerar um problema que faz parte de seu cotidiano, como é o caso da poluição.

Os alunos discutiram sobre as relações que existem entre outros elementos que fazem parte da paisagem analisada na atividade. Nesta perspectiva, com a percepção do aumento da população do município, pela expansão da área urbana, eles destacam a necessidade de criação de novas escolas, de casas, postos de saúde e outros equipamentos de infra-estrutura urbana que atendam as necessidades da população. Então, eles conseguiram estabelecer algumas relações entre os processos que ocorrem no espaço urbano, o aumento da população do município e a necessidade de serviços públicos, e as transformações espaciais relacionadas aos processos citados.

Sobre a experiência, os alunos relataram que:

São Leopoldo no ano de 1947 tinha menos urbanização e mais vegetação, pois as pessoas foram destruindo a maior parte da vegetação leopoldense para construir residências, prédios, escolas, postos de saúde etc., assim fazendo crescer cada vez mais a urbanização e com ela vindo a poluição do ar, do rio, das ruas, e do ambiente onde vivemos atualmente (Naína e

Geografia Ensino \& Pesquisa, v. 15, n.3, p. 129138, set./dez. 2011

Holgado, F. L.; Rosa, K. K 
Michele).

Alguns meandros do rio desapareceram causando modificações na área. (Lucas).

Com o mapa percebemos que há pouca vegetação e o curso do rio mudou... A evolução da cidade de São Leopoldo foi rápida. Áreas de vegetação perderam espaço para a zona urbana no decorrer dos anos. (Mateus).

O mapa mudou bastante em vários lugares... a população aumentou, construíram mais casas e prédios e com isso, diminuiu muito a área le vegetação e rural (Bruna e Natália).

Demonstra-se, assim, que os alunos conseguiram entender como a cidade está em constante transformação, ou seja, a cidade que eles conhecem hoje não foi sempre assim, não existiam elementos que fazem parte do seu cotidiano, como o ginásio municipal, por exemplo, fato que foi destacado nos seus comentários. Assim, a cidade, continuará com constantes modificações em seus diferentes espaços, e alguns elementos que conhecem deixarão de existir e novos elementos surgirão nesses espaços.

Também em relação à população, na observação das fotografias aéreas, os alunos perceberam que o processo de urbanização e diminuição das áreas rurais no período analisado. A migração das pessoas em direção à cidade, devido às possibilidades de trabalho e busca de melhor qualidade de vida, foram relacionadas pelos alunos com este processo de adensamento da população urbana. 0 aumento das vias de circulação também foi ser observado pelos alunos nas imagens, o que representa a maior circulação de veículos pelo município.

Alguns alunos conseguiram perceber as alterações na morfologia do rio dos Sinos, como os processos de canalização e retificação. Analisaram que o rio sofre um processo contínuo de transformações, tanto por influências antrópicas como por processos naturais. Entre as mudanças antrópicas, compreenderam a necessidade da construção do dique de contenção para evitar que as áreas urbanizadas próximas ao rio sofressem com as cheias, também relacionaram as transformações no rio devido à urbanização. Estas relações demonstram aos alunos que a paisagem sofre interferência de vários processos naturais, mesmo que a área estudada seja uma área urbana.

Os alunos, com a atividade, perceberam que a paisagem está em constante transformação, e o processo de urbanização está relacionado a ela. Essa paisagem urbana será composta por diferentes elementos, e perceber esses elementos como característicos dessa paisagem é importante, são eles que caracterizam 0 que se observa e 0 que se percebe. Com esses elementos verifica-se que a

cidade é uma aglomeração de pessoas (habitantes, visitantes) e de objetos (edifícios, casas, ruas). Em função dessas pessoas e desses objetos os espaços e a vida urbana se organizam. Esses elementos vão configurando uma paisagem urbana, sendo possível, assim, estudar a cidade como uma paisagem. Essa é sua forma, o conjunto formado pelos objetos que a compõem, pelos sons, pelos odores, pelas pessoas e seus movimentos. 0 estudo desses aspectos oferece pistas para a análise de outros elementos (CAVALCANTI, 2008, p.123).

Geografia Ensino \& Pesquisa, v. 15, n.3, p. 129138, set./dez. 2011

Olhares sobre a paisagem - a utilização de imagens de satélite e fotografias aéreas no ensino de Geografia
Nas atividades desenvolvidas foi possível promover um estímulo aos alunos a desenvolverem a percepção de que o espaço urbano, ou seja, o espaço em que eles vivem, que faz parte do seu cotidiano é composto por vários elementos, e a simples existência de um espaço urbano já indica transformações na paisagem devido a toda a influência humana que pode ser observada nas imagens. Então, pode-se perceber que 
A cidade, como trabalho humano, é a expressão da relação do homem com a natureza (a primeira e a segunda naturezas). Assim, as construções de casas e industrias, os calçamentos de quintais, os asfaltamentos de ruas e as canalizações dos córregos levam a retirada da vegetação e dos animais ali presentes e ajudam a configurar 0 ambiente urbano, dando-lhe um aspecto peculiar, um aspecto de ambiente construído (CAVALCANTI, 2008, p.100).

Sobre esse ambiente construído, os alunos puderam refletir durante a realização das atividades. Assim, a utilização das fotografias aéreas foi fundamental para estimular a percepção nos alunos sobre o espaço urbano, por ser um recurso visual que gera mais curiosidade nos alunos e por ser uma representação de um local que é conhecido por eles.

Dentre os elementos que geraram curiosidades nos alunos, pode-se citar: (a) o crescimento e o passado da cidade em que moram como desconhecidos; (b) as modificações na paisagem urbana; (c) o processo de obtenção das imagens e como criar legendas; (d) o manuseio de fotografias aéreas e imagens de satélite; (e) a forma como são adquiridos os produtos de Sensoriamento Remoto e diversas aplicações; (f) o interesse em estudar outros lugares utilizando imagens e fotografias aéreas; (g) a evolução e características do rio dos Sinos e de seu município.

\section{Possibilidades para novos olhares ...}

Com as atividades didáticas desenvolvidas em sala de aula apresentadas neste trabalho pode-se afirmar que as diversas possibilidades de aplicações dos produtos de Sensoriamento Remoto no ensino de Geografia na educação básica são importantes para se alcançar um melhor aproveitamento pelos alunos.

O uso de dados obtidos por Sensoriamento Remoto, como sequências de imagens de satélites e fotografias aéreas de diferentes anos, possibilita a análise das transformações temporais ocorridas na paisagem ao longo das ultimas décadas, como consequência das alterações antrópicas no desempenho de suas atividades econômicas e das transformações geradas pela ação de processos naturais. Constituindo-se, assim, um instrumental de análise geográfica pelos alunos.

Os dados de Sensoriamento Remoto instigaram a reflexão sobre a análise das relações dinâmicas e a representação em mapas temáticos. Desta forma, o uso de imagens de satélite e fotografias aéreas nas aulas da educação básica mostrou-se um importante recurso didático para extrair informações e realizar análises das paisagens em transformação que fazem parte da vida dos alunos. Pelo que foi discutido com os alunos durante a aplicação das atividades verificou-se que eles analisaram de forma efetiva os elementos que fazem parte de uma paisagem urbana e os processos que ocorrem nesse espaço.

Com o desenvolvimento da atividade proposta verificaram-se alguns encaminhamentos que podem dar prosseguimento ao tema estudado. Esses encaminhamentos foram feitos a partir de considerações feitas pelos alunos ao final da realização das atividades:

"Via internet e livros, e até visitando São Leopoldo." (Juhan)

Geografia Ensino \& Pesquisa, v. 15, n.3, p. 129138, set./dez. 2011

"Podemos estudar mais detalhes da cidade de hoje e de como era há vários anos atrás." (Naína) 
"Poderíamos fazer um passeio para aprofundar mais essa matéria." (Melissa)

"Fazendo uma maquete de uma cidade." (Jordana)

Com essas observações dos alunos pode-se perceber que a forma em que foi desenvolvida a atividade, e o fato de estar relacionada com um tema que está vinculado com 0 seu cotidiano, fez com que eles sugerissem caminhos a serem seguidos para dar prosseguimento ao estudo do tema. Demonstra-se que uma proposta diferenciada pode gerar uma reação diferente nos alunos, obtendo-se maior participação e interesse no que está sendo proposto e estudado em sala de aula.

Conforme apresentado nesta discussão, um dos aspectos principais do uso do Sensoriamento Remoto em sala de aula foi o interesse da turma no estudo do tema. No entanto, constata-se que ainda esse recurso é muito pouco utilizado nas aulas de Geografia, assim, devem-se buscar outras formas de utilizá-lo nas práticas cotidianas nas escolas para que se aproveite o apoio que pode fornecer ao ensino de Geografia. Portanto, os professores devem buscar entender mais sobre esses recursos e refletir sobre a melhor forma de utilização em práticas pedagógicas, para que se consiga um maior aproveitamento no processo de ensino aprendizagem.

\section{Referências Bibliográficas}

BRASIL. Ministério da Educação. Secretaria de Educação Fundamental Parâmetros Curriculares Nacionais. Terceiro e Quarto Ciclos do Ensino Fundamental - Geografia. Brasília, 1998.

Secretaria de Ensino Superior. Diretrizes Curriculares Nacionais: 1998-2000.

CAVALCANTE, Maria Madalena de Aguiar; BIESEK, Solange. O uso de tecnologia no ensino de Geografia: experiência na formação de professores. $10^{\circ}$ Encontro Nacional de Prática de Ensino em Geografia. 2010. Porto Alegre. Disponível em http://www.agb.org.br/XENPEG/artigos/GT/GT5/tc5\%20(84).pdf

CAVALCANTI, Lana de Souza. A Geografia escolar e a cidade: Ensaios sobre o ensino de Geografia para a vida urbana. Campinas, SP: Papirus, 2008

FRANCISCHETT, Mafalda Nesi. A Cartografia no Ensino de Geografia: Construindo os Caminhos do Cotidiano. Rio de Janeiro: Litteris, 2002.

PONTUSCHKA, Nídia Nacib; PAGANELLI, Tomoko lyda; CACETE, Núria Hanglei. Para ensinar e aprender Geografia. $3^{\mathrm{a}}$ ed. - São Paulo: Cortez, 2009 